\title{
Postherpetic Trigeminal Trophic Syndrome: An under recognized condition
}

\author{
Dhali TK ${ }^{1}$, Agrawal S ${ }^{2}$
}

\author{
${ }^{1}$ Associate Professor, Department of \\ Dermatology and Venereology,B. P. Koirala \\ Institute of Health Sciences, Dharan, Nepal. \\ ${ }^{2}$ Professor ,Department of Dermatology and \\ Venereology, B. P. Koirala Institute of Health \\ Sciences, Dharan, Nepal.
}

\author{
Correspondence \\ Dr. Tapan Kumar Dhali \\ Associate Professor \\ Department of Dermatology and Venereology \\ B. P. Koirala Institute of Health Sciences, \\ Dharan, Nepal.
}

Fax: 00977-25-520251

E-mail: tapan99@gmail.com

\section{Introduction}

Trigeminal trophic syndrome (TTS) is a rare complication after peripheral or central damage to the trigeminal nerve, characterized by sensorial impairment in the trigeminal nerve territory and self-induced skin ulceration. ${ }^{1}$ The different causes of TTS includes trigeminal nerve ablation, wallenberg syndrome (stroke/ vascular insufficiency), tumor, post-encephalitic, trauma, craniotomy, herpes zoster, herpes simplex, leprosy, syphilis, neurological complications from birth trauma. Trigeminal trophic syndrome may develop months to years after trigeminal nerve insult. Its most common presentation is a crescent-shaped ulceration within the trigeminal sensory territory.

\section{Case report}

A 65-year-old man presented to dermatology Out Patient Department with a 3-month history of an ulcer on the right side of his forehead. The lesions first appeared 5months after vesicobullous eruption over right forehead extending few centimeters towards scalp. In addition, he complained of tickling and prickling facial sensations, which had greatly intensified and affected the right side of his forehead since the time of active lesion. The ulcers, however, was painless. The patient reported regularly picking at and scratching the affected area. On cutaneous examination, single, $1 \mathrm{~cm}$ diameter, round shaped sharply demarcated superficial ulcer over a hyperpigmented plaque of size $3 \mathrm{~cm} \mathrm{X} 3 \mathrm{~cm}$ present over the right side of the forehead. There was also presence of multiple small, hyperpigmented scaly plaques with scar a few centimeters away from the ulcer on the same site (Picture 1). Cutaneous sensation was diminished to pain, temperature and touch over that area. Other systemic examination including eye was within normal. The patient was diagnosed as TTS due to herpes zoster based on:

(1) the presence of facial paraesthesia

(2) long history of repeated physical manipulation of the affected area

(3) unilateral painless ulceration and

(4) the history of dermatomal vesicular eruption.

Patient was put on gabapentin $1800 \mathrm{mg}$ /day in three divided doses along with occlusive dressing of ulcer with 
topical mupirocin cream. Patient was counseled and asked to trim his fingernails with wearing of gloves at bed time to reduce the self induced trauma. After one month patient didn't have much improvement of ulcer. The patient was continued gabapentin and advised injection triamcinolone acetonide sublesional $(5 \mathrm{mg} / \mathrm{ml} ; 1 \mathrm{ml}$ per visit) every 3weekly. On the first follow-up the patient had mild improvement however the patient was lost to follow up further.

\section{Discussion}

Trigeminal trophic syndrome is a rare entity in which cutaneous ulceration develops within trigeminal dermatomes ${ }^{1}$. TTS was first described as a cutaneous ulceration in the trigeminal dermatome by Wallenberg ${ }^{2}$ in 1901, with its first appearance in the English language literature noted by Loveman ${ }^{3}$ and McKenzie ${ }^{4}$ in 1933. The age of TTS presentation varies with patients as young as 14 months and as old as 94 years ${ }^{5,6}$. However, the mean age of presentation is reported at 57, with a female predominance of 2.2: $1^{5}$. The ala nasi is the most typical ulcer location, although lesions occur on the scalp, forehead, cheek, temple, ear, upper lip, palate, and jaw have also been described in the literature ${ }^{7}$. Alar ulceration occurs in noncartilaginous areas, forms the distinctive "ulceration en arc." The underlying mechanism is repetitive self-mutilation of the skin to alleviate the perceived paresthetic irritation ${ }^{5,8-9}$. A review of the literature shows that most cases of TTS are caused by trigeminal nerve ablation for the treatment of trigeminal neuralgia or stroke of the cerebellum or of the brainstem ${ }^{5,10}$. Other causes include craniotomy, head trauma, infections (such as herpes, leprosy, or Gradenigo syndrome), syringobulbia, and mental impairment ${ }^{11}$.

Herpes zoster is rare cause of TTS affecting first branch of trigeminal nerve. After herpes zoster heal most of the patients complain is limited to post herpetic neuralgia. Only in a few patients develop chronic TTS ulceration. There is no data available showing the incidence of TTS following herpes zoster. It may be in the range of TTS following local anesthesia after trigeminal rhizotomy, which is up to $16 \%^{11}$.

The pathogenesis underlying the sensation of itch in TTS is not known. The mechanisms are more or less same irrespective of etiology and may share with post herpetic itch. Herpes zoster causes the degeneration of peripheral sensory neurons followed by post-herpetic dysaesthesias. It has been proposed that post-herpetic itch is generated by central itch neurons, when the usual afferent input is being deprived, akin to "phantom-limb pain"12. Neuropathic itch is known to drive patients to scratch incessantly.

The diagnosis is often made on clinical grounds with the triad of trigeminal anaesthesia, facial paresthesias, and unilateral ulceration but should be differentiated from basal cell carcinoma, squamous cell carcinoma, lymphoma, infections (such as varicella zoster or herpes simplex virus infection, deep fungal infection, leishmaniasis, leprosy, tertiary syphilis, or tuberculosis), temporal arteritis, pyoderma gangrenosum, Wegener granulomatosis, or factitial disorders.

TTS is a difficult condition to manage. Informing the patient about auto-mutilation of the affected facial areas prevents further irritation and supports healing. It is a crucial step prior to the surgical repair of TTS (e.g., cotton gloves, taped fingers, trimmed fingernails, nasal shield). Regular hydrocolloid dressings and rheologic therapy may improve wound healing. Medications like vitamin B supplementation ${ }^{13}$, diazepam, amitriptylline ${ }^{13,14}$, chlorpromazine $^{15}$, carbamazepine ${ }^{16}$, gabapentin ${ }^{17}$, acyclovir ${ }^{18}$, have been tried with variable success. Other treatment options are ionizing radiation ${ }^{3}$, transcutaneous electrical nerve stimulation (TENS) ${ }^{19}$.Surgicalmodalities like sublesional triamcinolone ${ }^{18}$, reconstructive plastic surgeries with contralateral skin graft $^{20}$, placement of surgical prosthesis to mask the affected area ${ }^{21}$ have been reported. In our case we treated with gabapentin to reduce the paraesthesias and sublesional steroid injection which acts as an anti-inflammatory agent to reduced the fibrosis and promoting the reepitheliazation of the ulcer base. Occlusive dressing is an important aspect of this type of ulcer management, which probably helps to protect the skin from further trauma and keep the ulcer base hydrated. The role of acyclovir in fully developed ulcer of TTS is controversial though have been tried in

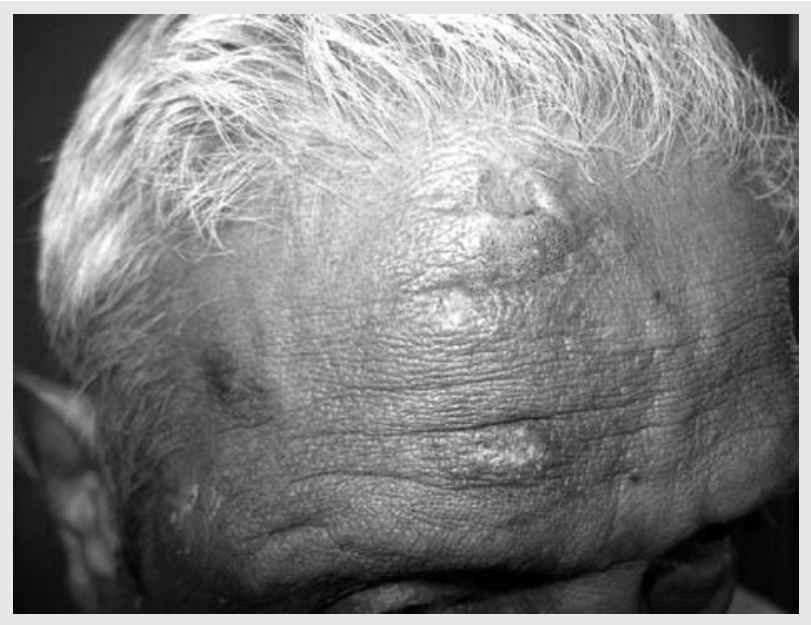

Picture 1 Multiple, small scaly plaque, scar and hyper pigmentation with central ulceration present over forehead 
the past ${ }^{18}$.

\section{Conclusion}

This case highlights a rare but important clinical entity that may be clinically mistaken for a cutaneous malignancy. TTS is likely to be more common than reported, with a globally aging population along with AIDS patients burdened with a high incidence herpes virus infection. Though it is very difficult to predict during active stage of herpes zoster that which patient will develop the TTS but regular follow-up and active intervention during post herpetic neuralgia particularly in elderly patients certainly prevent the condition. However, the best way to prevent herpes zoster and TSS in association with it is to decrease the incidence of varicella infection by immunization.

\section{References}

1. Arasi R., McKay, M., Grist, W. Trigeminal trophic syndrome. Laryngoscope 1988; 98: 1330-1333.

2. Wallenberg A. Klinische Beitrage zur Diagnostik acuter Herderkrankungen des Verlangerten Marks und der Bruke. Dt Z Nervenheeilk 1901; 19: 227-231.

3. Loveman $\mathrm{AB}$. An unusual dermatosis following section of the fifth cranial nerve. Arch Dermatol Syph 1933; 28 : 369- 375 .

4. McKenzie KG. Observations on the results on the operative treatment of trigeminal neuralgia. Can Med Assoc 1933; 29: 492-496.

5. Weintraub E, Soltani K, Hekmatpanah J, Lorincz Al. Trigeminal trophic syndrome. A case and review. J Am Acad Dermatol 1982; 6: 52-57.

6. Lyon CC, Mughal MZ, Muston HL. Herpetic trigeminal trophic syndrome in an infant. J R Soc Med 2001; 94: 135-137.

7. Setyadi HG, Cohen PR, Schulze KE, et al. Trigeminal trophic syndrome. South Med J. 2007; 100(1): 43-48.

8. Dicken $\mathrm{CH}$. Trigeminal trophic syndrome. Mayo Clin Proc. 1997; 72(6): 543-545.

9. Sadeghi P, Papay FA, Vidimos AT. Trigeminal trophic syndrome- report of four cases and review of the literature. Dermatol Surg. 2004; 30 (5): 807-812.

10. Hancox JG, Wittenberg GF, Yosipovitch G. A patient with nasal ulceration after brain surgery [letter]. Arch Dermatol. 2005; 141(6): 796-798.

11. Goodnight JW, Calcaterra T. Trigeminal trophic syndrome: a report of two cases and review. Am J Otolaryngol 1994; 15: 219-222.

12. Oaklander AL, Cohen SP, Raju SV. Intractable postherpetic itch and cutaneous deafferentation after facial shingles. Pain 2002; 96: 9-12.

13. Ferrara G, Argenziano G, Cicarelli G, Cusano F, Delfino M. Postapopletic trigeminal trophic syndrome. J Eur Acad Dermatol Venereol 2001; 15:153-155.

14. Finlay AY. Trigeminal trophic syndrome. Arch Dermatol $1979 ; 115: 1118$.

15. Kavanagh GM, Tidman MJ, McLaren KM, Goldberg A, Benton EC. The trigeminal trophic syndrome: an underrecognized complication. Clin Exp Dermatol 1996; 21: 299-301.

16. Bhushan M, Parry EJ, Telfer NR. Trigeminal trophic syndrome: successful treatment with carbamazepine. $\mathrm{Br} \mathrm{J}$ Dermatol 1999; 141: 758-759.

17. Parrish S, Francis AP, Allison TV. Trigeminal Trophic Syndrome-Report of four cases and review of the literature Dermatol Surg 2004; 30: 807-812.

18. Shea CR, Scott RA, Tompkins SD. Herpetic trigeminal trophic syndrome: treatment with acyclovir and sublesional triamcinolone. Arch Dermatol 1996; 132: 613-614.

19. Westerhof W, Bos JD. Trigeminal trophic syndrome: a successful treatment with transcutaneous electrical stimulation. Br J Dermatol 1983; 108: 601-604.

20. Litschel R, Winkler H, Dazert S, Sudhoff H. Herpes zoster associated trigeminal trophic syndrome: a case report and review. Eur Arch Otorhinolaryngol 2003; 260: 86-90.

21. Preston PW, Orpin SD, Tucker WF, Zaki I. Successful use of a thermoplastic dressing in two cases of the trigeminal trophic syndrome. Clin Exp Dermatol 2006; 31: 525-527. 